\title{
Erratum to hydrogen/oxygen mixed gas inhalation improves disease severity and dyspnea in patients with Coronavirus disease 2019 in a recent multicenter, open-label clinical trial
}

\author{
Wei-Jie Guan $^{1 \#}$, Chun-Hua Wei ${ }^{2,3 \#}$, Ai-Lan Chen ${ }^{4,5 \#}$, Xiao-Cong Sun ${ }^{6,7}$, Guang-Yun Guo ${ }^{8}$, Xu Zou ${ }^{9,10}$, \\ Jin-Dong Shi ${ }^{10,11}$, Pei-Zhen Lai ${ }^{12}$, Ze-Guang Zheng ${ }^{1}$, Nan-Shan Zhong ${ }^{1}$
}

${ }^{1}$ State Key Laboratory of Respiratory Disease, National Clinical Research Center for Respiratory Disease, Guangzhou Institute of Respiratory Health, The First Affiliated Hospital of Guangzhou Medical University, Guangzhou Medical University, Guangzhou, China; ${ }^{2}$ Department of Respiratory Medicine, Weifang Wei'en Hospital, Weifang, China; ${ }^{3}$ Department of Respiratory Medicine, Wuhan Hanyang Hospital, Wuhan, China; ${ }^{4}$ Department of Cardiology, The First Affiliated Hospital of Guangzhou Medical University, Guangzhou Medical University, Guangzhou, China; ${ }^{5}$ Department of Respiratory and Critical Care Medicine, Wuhan Hankou Hospital, Wuhan, China; ${ }^{6}$ Intensive Care Unit, Affiliated Hospital of Guangdong Medical University, Zhanjiang, China; ${ }^{7}$ Intensive Care Unit, Shishou Hospital of Traditional Chinese Medicine, Shishou, China; ${ }^{8}$ Department of Respiratory and Critical Care Medicine, Wuhan Pulmonary Hospital, Wuhan, China; ${ }^{9}$ Department of Respiratory and Critical Care Medicine, Guangdong Hospital of Traditional Chinese Medicine, Guangzhou, China; ${ }^{10}$ Department of Infectious Diseases, Leishenshan Hospital, Wuhan, China; ${ }^{11}$ Department of Respiratory and Critical Care Medicine, Shanghai Fifth People's Hospital, Shanghai, China; ${ }^{12}$ Institute of Biochemistry and Molecular Biology, College of Medicine, National Taiwan University, Taipei

"These authors contributed equally to this work.

Correspondence to: Nan-Shan Zhong. State Key Laboratory of Respiratory Disease, National Clinical Research Center for Respiratory Disease, Guangzhou Institute of Respiratory Health, The First Affiliated Hospital of Guangzhou Medical University, 151 Yanjiang Road, Guangzhou, China. Email: nanshan@vip.163.com.

doi: $10.21037 /$ jtd-2020-062

View this article at: http://dx.doi.org/10.21037/jtd-2020-062

Erratum to: J Thorac Dis 2020;12:3448-52.

Hydrogen/oxygen mixed gas inhalation improves disease severity and dyspnea in patients with Coronavirus disease 2019 in a recent multicenter, open-label clinical trial

In the article that appeared on Page 3448-3452, Vol 12, No 6 (June 2020) Issue of the fournal of Thoracic Disease (fTD) (1), there is a numerical error occurred in the following sentence:

"On the basis of standard-of-care (3), patients in treatment group inhaled $\mathrm{H}_{2}-\mathrm{O}_{2}(66 \%$ hydrogen; $33 \%$ oxygen) at $6 \mathrm{~L} / \mathrm{min}$ via nasal cannula by using the Hydrogen/Oxygen Generator (model AMS-H-03, Shanghai Asclepius Meditec Co., Ltd., China) daily until discharge [see Figure E1 in Online Supplement (http://dx.doi.org/10.21037/jtd-2020-057)]."

The number given as "6 $\mathrm{L} / \mathrm{min}$ " should have been " $3 \mathrm{~L} / \mathrm{min}$ ". The sentence should read:

"On the basis of standard-of-care (3), patients in treatment group inhaled H2-O2 (66\% hydrogen; 33\% oxygen) at $3 \mathrm{~L} / \mathrm{min}$ via nasal cannula by using the Hydrogen/Oxygen Generator (model AMS-H-03, Shanghai Asclepius Meditec Co., Ltd., China) daily until discharge [see Figure E1 in Online Supplement (http://dx.doi.org/10.21037/jtd-2020-057)].”

This numerical error does not affect the results or conclusions of the study.

The authors regret the error. 
Open Access Statement: This is an Open Access article distributed in accordance with the Creative Commons AttributionNonCommercial-NoDerivs 4.0 International License (CC BY-NC-ND 4.0), which permits the non-commercial replication and distribution of the article with the strict proviso that no changes or edits are made and the original work is properly cited (including links to both the formal publication through the relevant DOI and the license). See: https://creativecommons.org/ licenses/by-nc-nd/4.0/.

\section{References}

1. Guan WJ, Wei CH, Chen AL, et al. Hydrogen/oxygen mixed gas inhalation improves disease severity and dyspnea in patients with Coronavirus disease 2019 in a recent multicenter, open-label clinical trial. J Thorac Dis 2020;12:3448-52.

Cite this article as: Guan $\mathrm{WJ}$, Wei $\mathrm{CH}$, Chen $\mathrm{AL}$, Sun $\mathrm{XC}$, Guo GY, Zou X, Shi JD, Lai PZ, Zheng ZG, Zhong NS. Erratum to hydrogen/oxygen mixed gas inhalation improves disease severity and dyspnea in patients with Coronavirus disease 2019 in a recent multicenter, open-label clinical trial. J Thorac Dis 2020;12(8):4591-4592. doi: 10.21037/jtd-2020-062 